\title{
Anthrovision
}

Vaneasa Online Journal

$4.1 \mid 2016$

Visual Creativity and Narrative Research in and on Oceania

\section{Barbara Glowczewski, Totemic Becomings. Cosmopolitics of the Dreaming} Book Review

\section{Gerko Egert}

\section{OpenEdition \\ Journals}

\section{Electronic version}

URL: http://journals.openedition.org/anthrovision/2291

DOI: 10.4000/anthrovision.2291

ISSN: 2198-6754

Publisher

VANEASA - Visual Anthropology Network of European Association of Social Anthropologists

\section{Electronic reference}

Gerko Egert, «Barbara Glowczewski, Totemic Becomings. Cosmopolitics of the Dreaming », Anthrovision [Online], 4.1 | 2016, Online since 31 December 2016, connection on 23 September 2020. URL : http:// journals.openedition.org/anthrovision/2291 ; DOI : https://doi.org/10.4000/anthrovision.2291

This text was automatically generated on 23 September 2020.

(c) Anthrovision 


\section{Barbara Glowczewski, Totemic Becomings. Cosmopolitics of the Dreaming}

Book Review

\section{Gerko Egert}

\section{REFERENCES}

Glowczewski, Barbara. Totemic Becomings. Cosmopolitics of the Dreaming / Devires Totêmicos. Cosmopolítica do sonho. [Bilingual Edition: English - Portuguese] Translated by Jamille Pinheiro with Abrahão de Oliveira Santos. Helsinki and Saõ Paulo: n-1 publications.

1 Barbara Glowczewski's book Totemic Becomings. Cosmopolitics of the Dreaming begins with the visual: the white and red lines of the ritual body painting of Melody Napurrurla (Lajamanu, 1984) lure the reader into the manifold worlds and cartographies of Warlpiri cosmologies and beyond. The Brazilian publisher, $n-1$, produces what he calls “object-books" with a special touch for each title. For Totemic Becomings, one or several hand painted red lines cross the side of each book as if continuing the body painting that features on the front and back pages. 
Barbara Glowczewski: Totemic Becomings

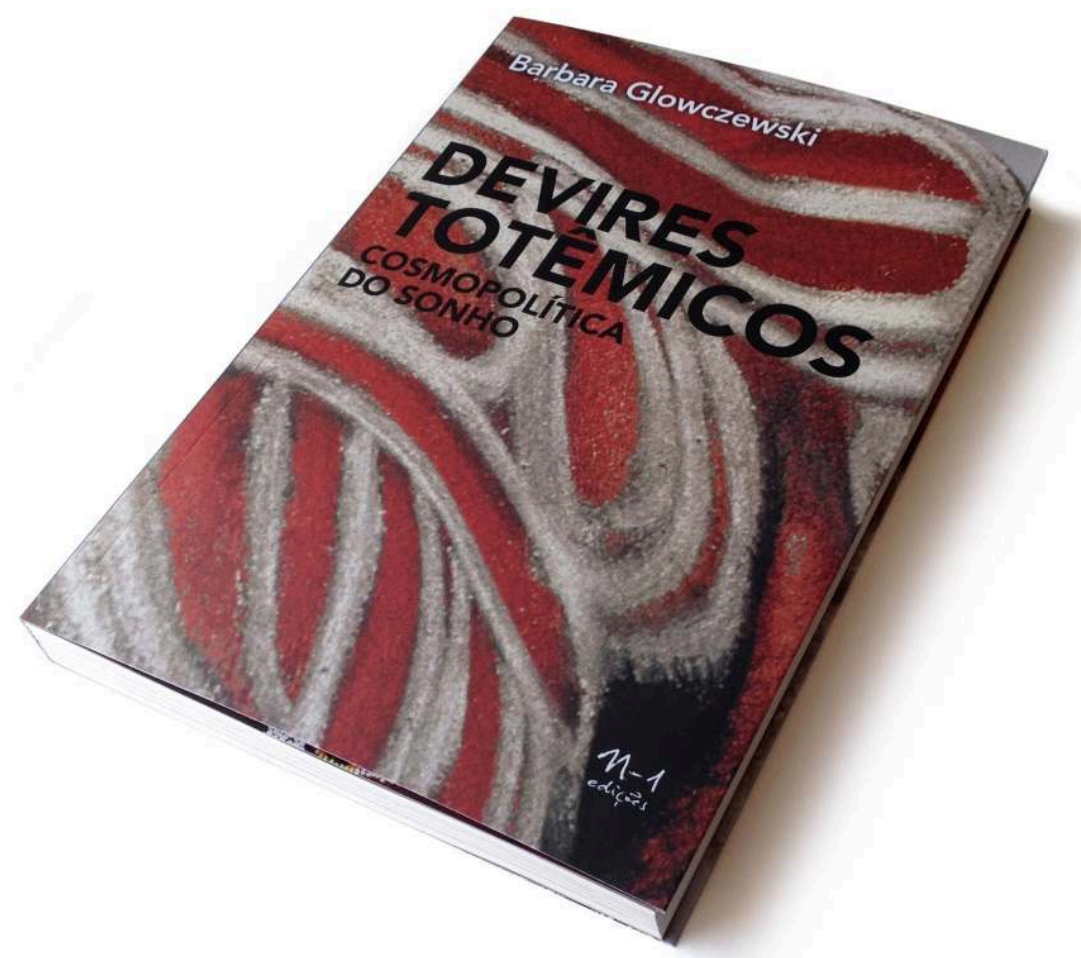

n-1 Publications 
Yumurrpa Yarla [site of the Yam Dreaming], 1991, acrylic on canvas by Yulyulu Napurrurla, $124 \times 124 \mathrm{~cm}$

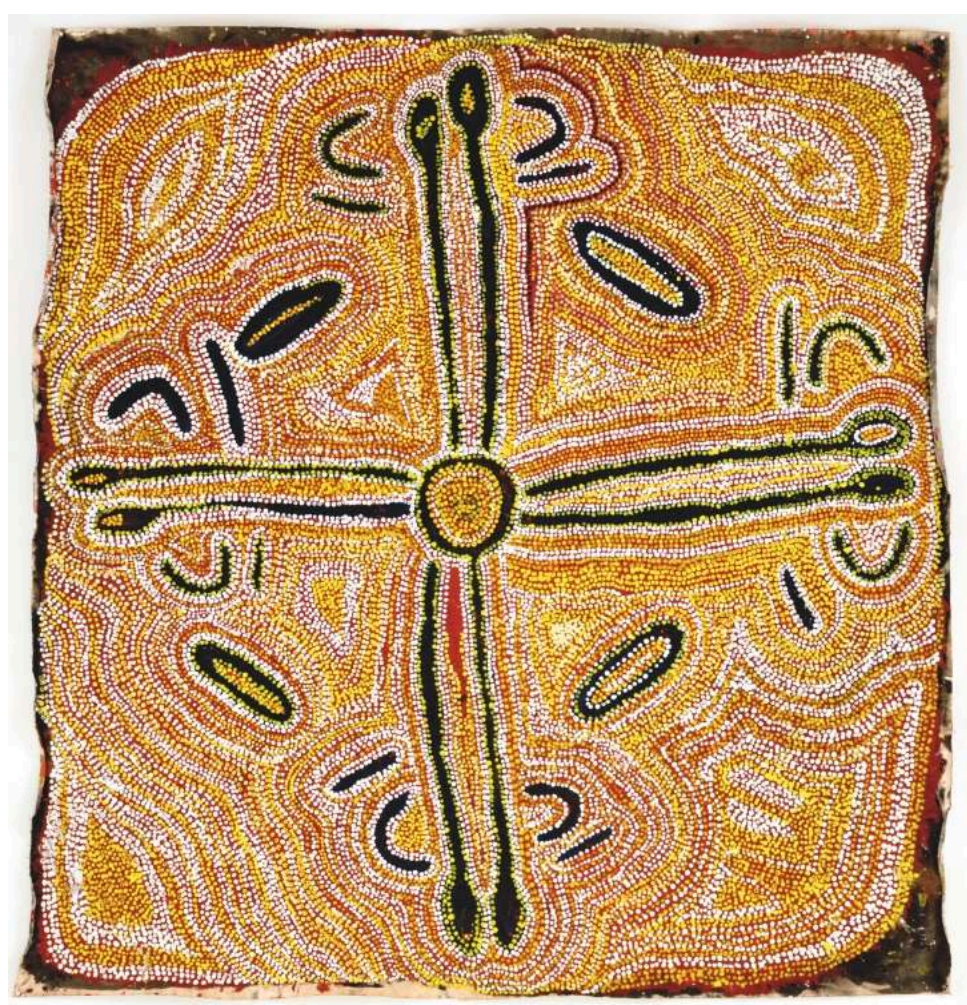

Lajamanu, Australia, private collection

Published in Totemic Becomings, inside cover

Opening the book the reader is offered another cartography: Yumurrpa Yarla [site of the Yam Dreaming] (Yulyulu Napurrurla, 1991). Composed as a rich assemblage of images and text, the book continues as a journey through drawings, photos, and notebook sketches, which inspire the reader to flip back and forth through the pages. ${ }^{1}$ Moreover, the reader can enter the bilingual book from both sides to explore the series of Glowczewski's text from the last 30 years as well as the manifold pictures - which even differ in the English and Portuguese part.

3 The text contained in the volume is also full of images: Already in the first pages, Glowczewski charts the complex cartographies of Warlpiri Dreaming cosmologies by following a meandering narrative that moves between Warlpiri "businesswomen" in Central Australia performing a ritual with a sacred rope and the wanderings of a boy in Fernand Deligny's movie Le moindre geste. These movements "unfold across the landscape" (16) and connect these two situations across various space-time differences. Yet another movement that unfolds throughout the text is the movement between philosophy and anthropology: as Glowczewski weaves her description with the unfolding of theoretical concepts, the demarcations between the two disciplines vanish. In Totemic Becomings, concepts like dreaming, ritual, law, and travel are immanent to the numerous descriptions of vibrant sensations. Here, perception and thinking are mutually imbricated, creating what the anthropologist calls a "cosmopolitics of the dreaming." 
Warlpiri women dancing ngatijirri Budgerigar Dreaming

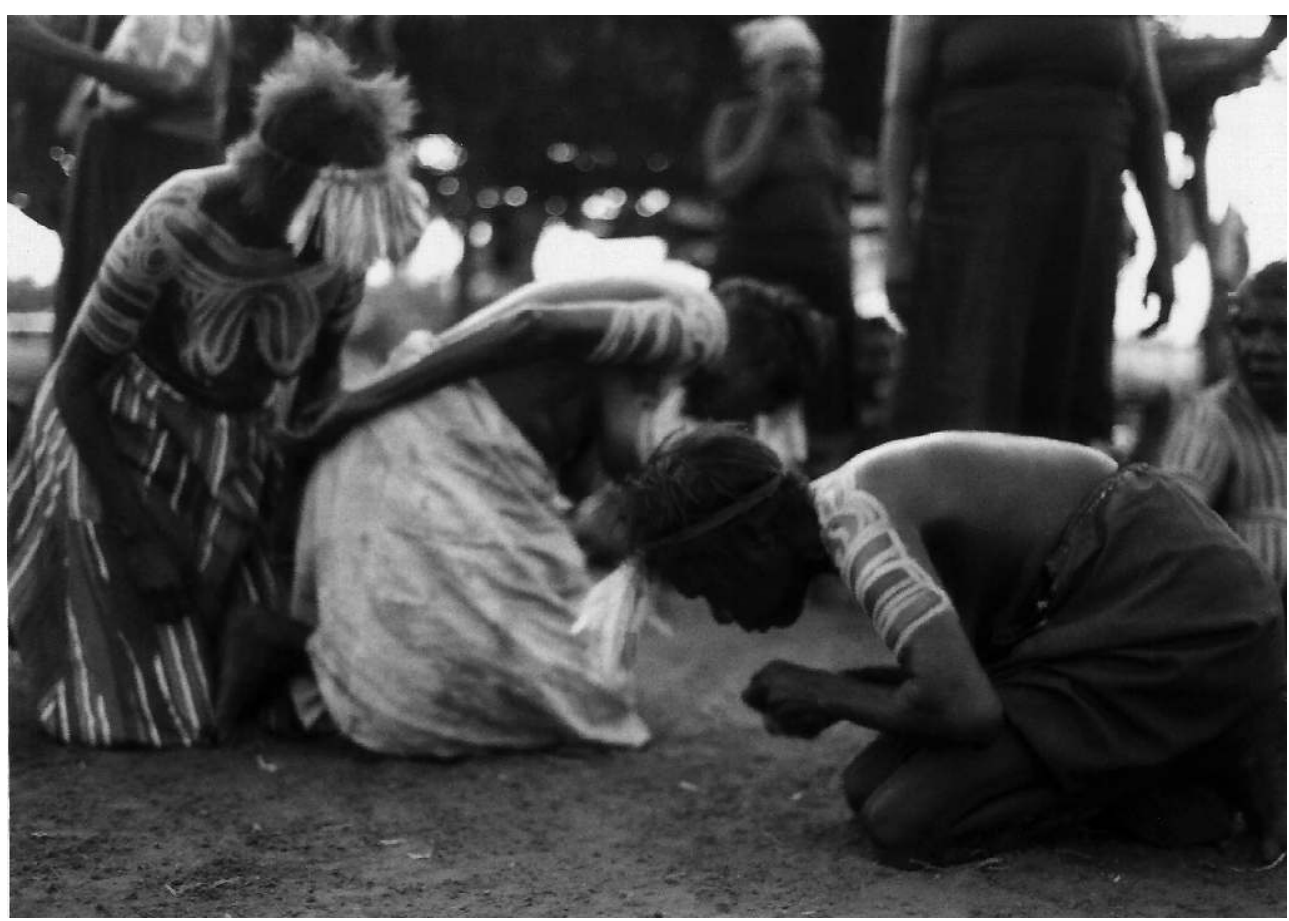

Published in Barbara Glowczewski, Totemic Becomings (6-7).

Photo by Barbara Glowczewski

4 The Warlpiri concept of the dream exceeds - as Glowczewski thoroughly argues - the individual as well as the human in many ways. Dreams do not belong to, nor do they give us a platform to interpret the inner psyche. Rather, dreams create a complex cartography that spans various modalities of time and space. The moving songlines weave together experiences with mythic stories, totemic powers, and travelling bodies. Yet, they do not remain within the realm of the imaginary or the unreachable mythic past - they operate as an immanent cartography. These cartographies are full of movement and process - Glowczewski writes of "cartographic work" (69) or "cartographic effort" (70) - and by that they produce new connections and new stories. The cartographies of dreaming are actualised in the ritual dances, and thus become part of an ongoing transformation of the world. These "totemic becomings" cannot be reduced to the displacement of the human body; they transversally cross images and matter, stories and songs, animals and plants, atmosphere and land, kinship and cosmology. Dreaming is, as Glowczewski explains, "the condition of life and of every transformation" (60). As transformative forces, dreams operate in interrelated fields as diverse as: sickness and healing (Chapter: "Shamans"), belief and religious practice (Chapter: "Is God a Dream(ing)?"), or gender and engendering (Chapter: "Acting and Becoming"). ("Shamans" and "Is God a Dream(ing)?" are excerpts from Les Rêveurs du désert, Plon, 1989, which has been published in full in English as Desert Dreamers, Univocal, 2016). 


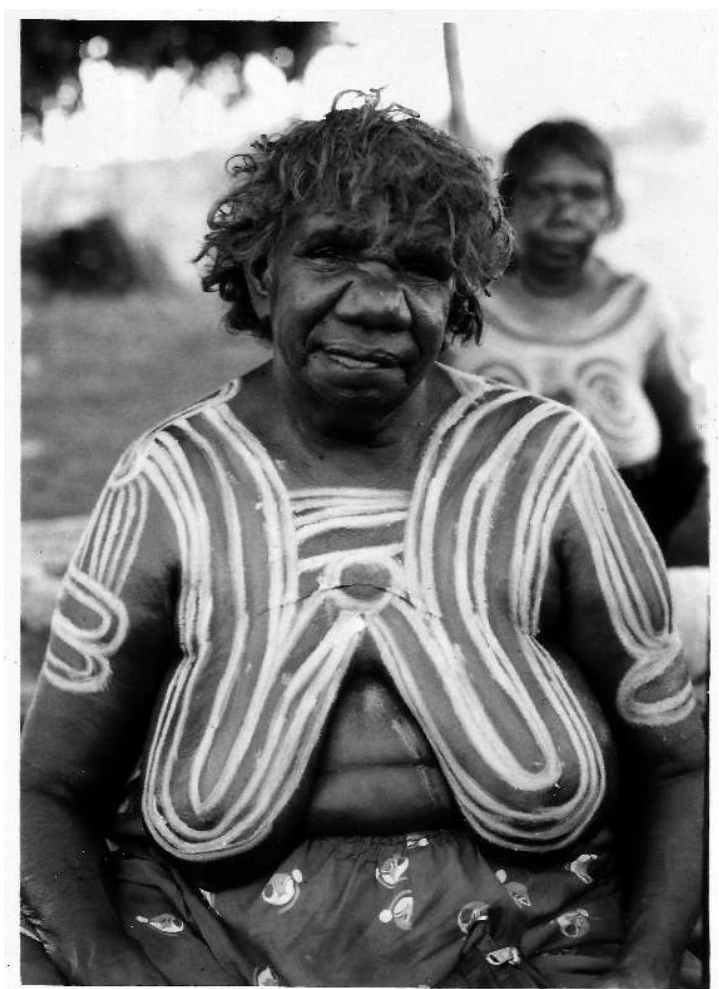

Painted with the cave and sand dunes of Yinapaka

Published in Barbara Glowczewski, Totemic Becomings (104).

Photo by Barbara Glowczewski

5 Throughout these chapters, the book follows the movements of a "constantly reproducing heterogeneity" (36). Even the most universal concept of the Hypercube does not provide the reader with a total overview, but with a pluriverse of relations thus foregrounding the multiple perspectives of kinship. The dreams and cartographies Glowczewski engages call for an asignifying analysis²: She does not interpret them as mere representations of an object or a situation, she follows their immanent forces, movements, and becomings of time, history, land, myths, bodies, and totems.

By providing a processual and relational cartography of Warlpiri songlines, the book questions the notion of many familiar concepts such as dreams, law, gender, and movement. By following the "totemic becomings," the book also challenges fundamental dichotomies of subject/object, movement/stasis, and agency/passivity. Yet Glowczewski does not project a distant and disconnected word. She does not offer Warlpiri movement as a foil to Western stillness, but shows how movement itself cannot be reduced to an elitist cosmopolitanism. She thus raises the question of how movement can become the possibility of escaping individual displacement. How can movement compose an "undercosmopolitanism" as Fred Moten writes (2014: 54)? Glowczewski's book offers an engagement with a world very much entangled in the current political struggles of land rights, police violence, and the capitalist logics of the (art) market. Within these transversal relations, Totemic Becomings articulates its political, cosmological as well as ecological force. Glowczewski's politics is not restricted to the state or the public realm, but operates in an "eco-logical" or "ecosophical" manner (Guattari 2000) cutting across realms of the social, the mental, 
and the environmental. By interlacing cosmological, aesthetic, and activist practices, the book opens up the possibility of another world and thereby enhances what Glowczewski describes as anthropology's responsibility: "the heterogeneous diversity on all levels in such way that culture and nature are not reified as fixed domains but understood as symbolic 'milieu' that people can transform to stimulate improved coexistence" (40).

\section{BIBLIOGRAPHY}

Moten, Fred. 2014. Notes on Passage (The New International of Sovereign Feelings). Palimpsest: A Journal on Women, Gender, and the Black International 3(1): 51-74

Guattari, Félix. 2000. The Three Ecologies. London, New Brunswick: The Athlone Press.

\section{NOTES}

1. A selection of Glowczewski's notebooks, films and photos can be accessed here: http:// www.odsas.net/index.php?action=set_category\&cat=aut\&value $=60$

2. These asignifying techniques are in many ways connected to the schizoanalyic concepts of Félix Guattari. See especially chapter 1 and the transcripts of two seminars that Glowczewski held together with Guattari, which are documented in chapters 2 and 3 of the book.

\section{AUTHOR}

\section{GERKO EGERT}

Ghent University, Studies in Performing Arts and Media (S:PAM)

gerkomail@gmail.com 